Supporting Information

\title{
Ag Nanoparticles Embedded in Multi-Shell Carbon Nanoparticles for Microwave Absorption
}

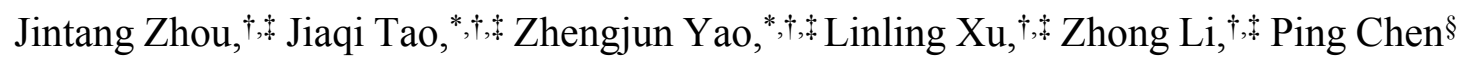

$\dagger$ College of Materials Science and Technology, Nanjing University of Aeronautics and Astronautics, Nanjing, 211100, Jiangsu, People's Republic of China

$\$$ Key Laboratory of Material Preparation and Protection for Harsh Environment (Nanjing University of Aeronautics and Astronautics), Ministry of Industry and Information Technology, Nanjing, 211100, Jiangsu, People's Republic of China

$\S$ School of Electronic Science and Engineering, Nanjing University, Nanjing, Jiangsu 210023 People's Republic of China

* Corresponding author. College of Materials Science and Technology, Nanjing University of Aeronautics and Astronautics, Nanjing, 211100, Jiangsu, People's Republic of China.

Phone: +8613252028392

E-mail address: 1012737697@qq.com (J. Tao), yaozj1921@126.com (Z. Yao). 


\section{Contents}

Table S1. Synthetic raw materials and ratio.

eqs S1-S4. The chemical reactions involved in the manuscript.

Figure S1. Element Mapping of SEM.

Figure S2. EDX results of SEM

Figure S3. The BET results of the sample.

Figure S4. Optimal RL-thickness curve and 1/4 wavelength function curve.

Figure S5. Permeability parameters of Ag/C-0 (a), Ag/C-1 (b), Ag/C-2 (c) and $\operatorname{Ag} / \mathbf{C - 3}$ (d).

Figure S6. Electromagnetic parameters and MA performance of $15 \mathrm{wt} \%(\mathrm{a}, \mathrm{d})$,

$20 \mathrm{wt} \%(\mathrm{~b}, \mathrm{e})$ and $30 \mathrm{wt} \%(\mathrm{c}, \mathrm{f})$ filling ratio. 
Table S1.

Synthetic raw materials and ratio.

\begin{tabular}{lccccc}
\hline Samples & AgNO $_{3}(\mathbf{g})$ & Deionized water $(\mathbf{m l})$ & $\mathbf{3 - A P}(\mathbf{g})$ & $\mathbf{H C H O}(\mathbf{m l})$ & Acetone \\
\hline $\mathrm{Ag} / \mathrm{C}-0$ & 0 & 300 & 1 & 2 & 0 \\
$\mathrm{Ag} / \mathrm{C}-1$ & 0.15 & 300 & 1 & 2 & 200 \\
$\mathrm{Ag} / \mathrm{C}-2$ & 0.20 & 300 & 1 & 2 & 200 \\
$\mathrm{Ag} / \mathrm{C}-3$ & 0.25 & 300 & 1 & 2 & 200 \\
\hline
\end{tabular}

eqs S1-S4:

$2 \mathrm{Ag}^{+}+2 \mathrm{NH}_{3} \cdot \mathrm{H}_{2} \mathrm{O}=\mathrm{Ag}_{2} \mathrm{O}(\downarrow)+\mathrm{H}_{2} \mathrm{O}+2 \mathrm{NH}_{4}^{+}$

$\mathrm{Ag}_{2} \mathrm{O}+4 \mathrm{NH}_{3} \cdot \mathrm{H}_{2} \mathrm{O}=2\left(\mathrm{Ag}\left(\mathrm{NH}_{3}\right)_{2} \mathrm{OH}+3 \mathrm{H}_{2} \mathrm{O}\right.$

$\mathrm{HCHO}+2 \mathrm{Ag}_{2} \mathrm{O}=\mathrm{H}_{2} \mathrm{O}+\mathrm{CO}_{2}(\uparrow)+4 \mathrm{Ag}(\downarrow)$

$\mathrm{HCHO}+4\left(\mathrm{Ag}\left(\mathrm{NH}_{3}\right)_{2} \mathrm{OH}=\left(\mathrm{NH}_{4}\right)_{2} \mathrm{CO}_{3}+6 \mathrm{NH}_{3}(\uparrow)+4 \mathrm{Ag}(\downarrow)+2 \mathrm{H}_{2} \mathrm{O}\right.$ 


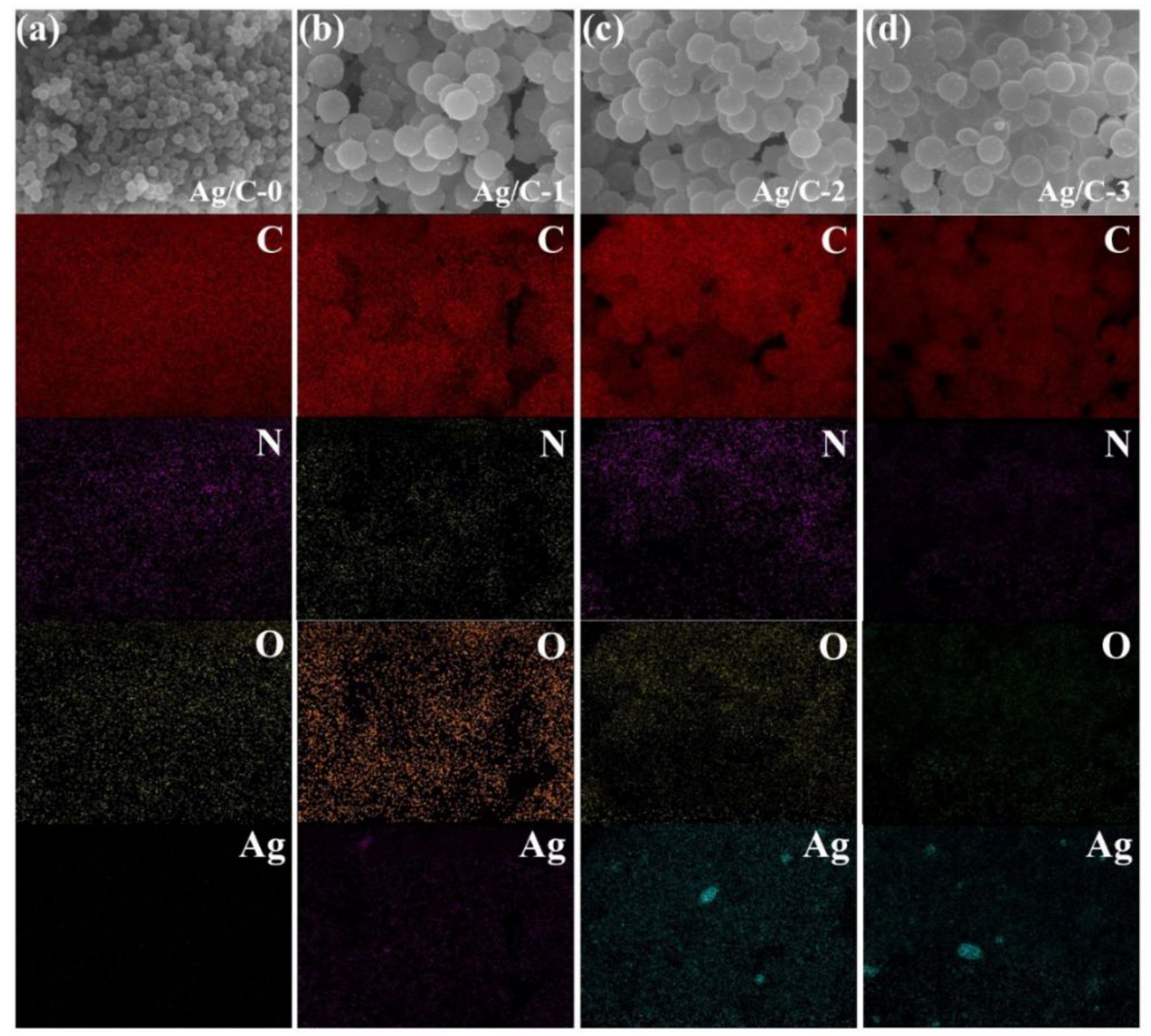

Figure S1. Element Mapping of SEM.
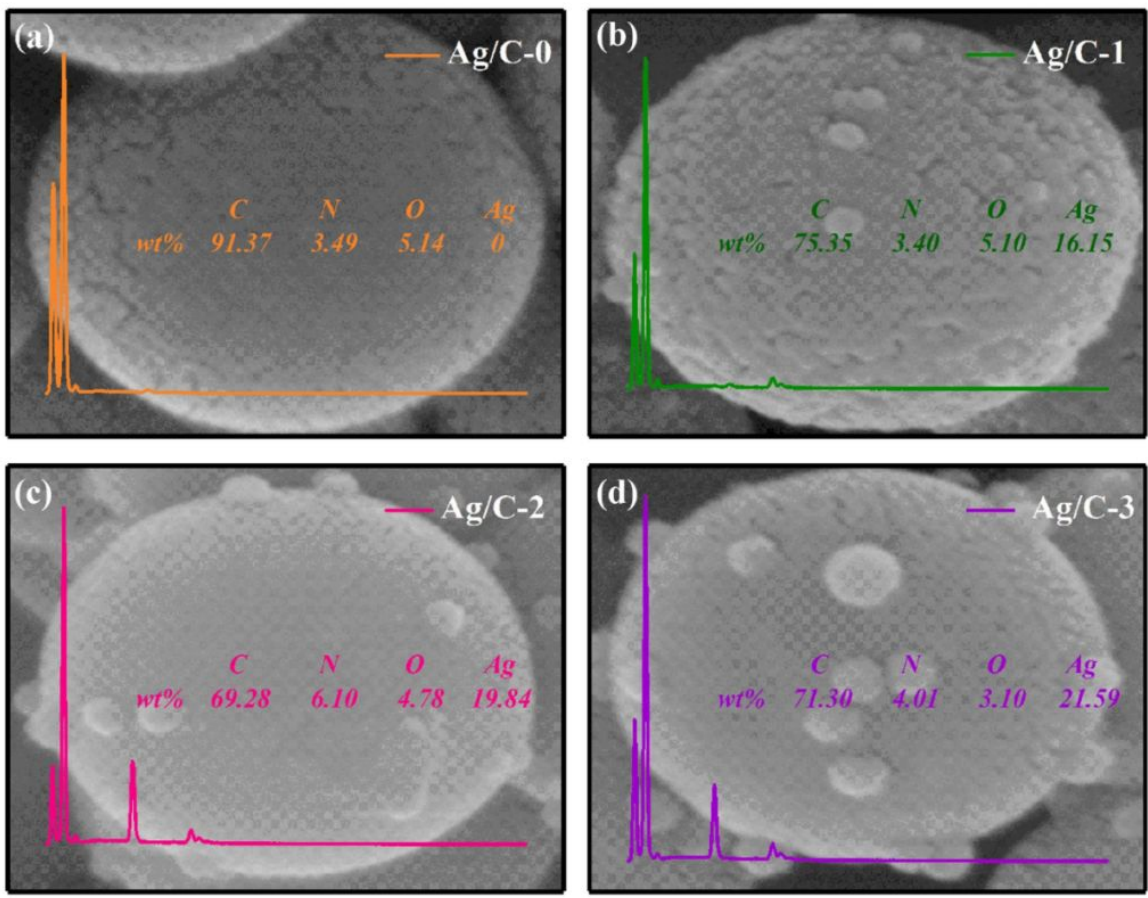
Figure S2. EDX results of SEM.
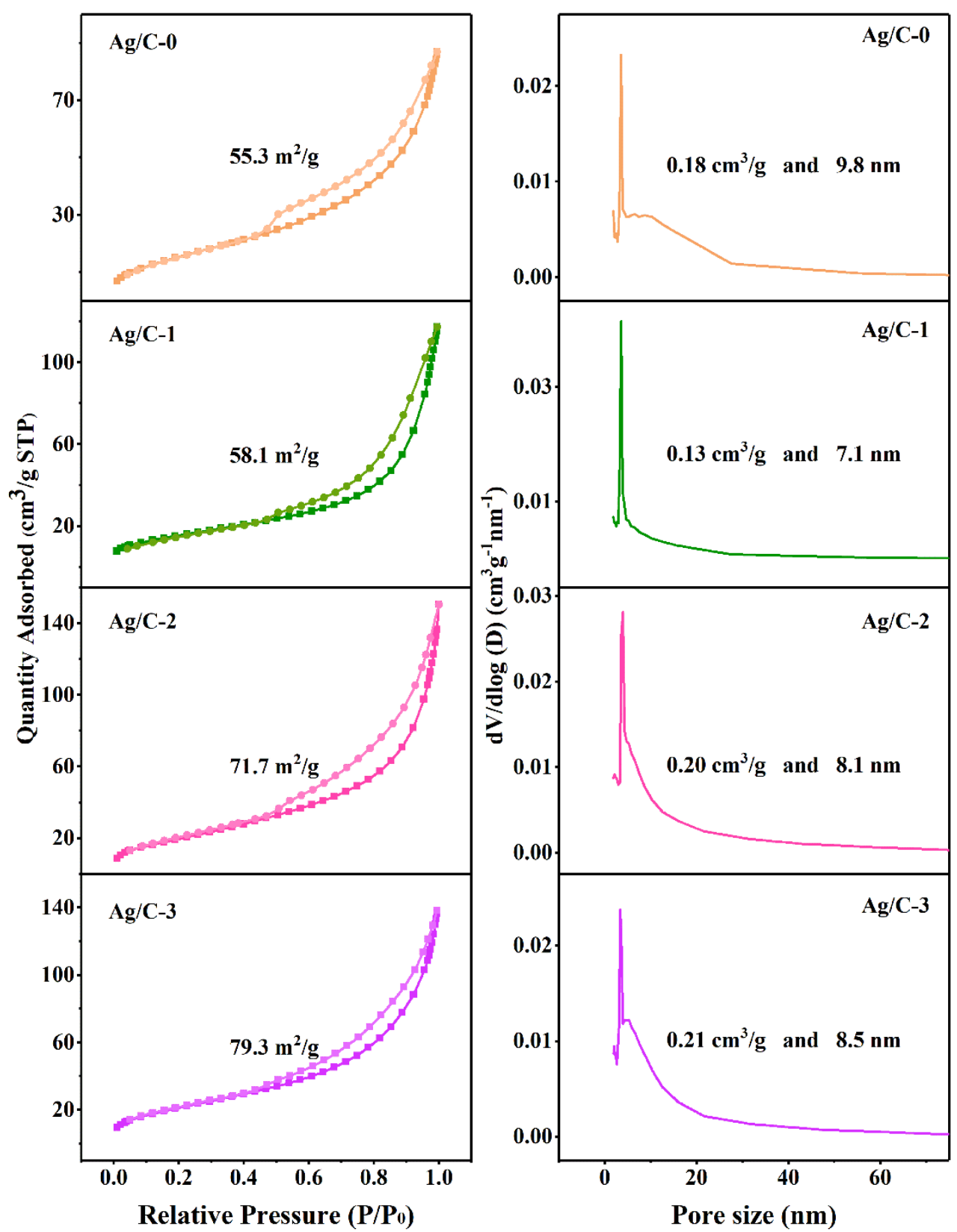

Figure S3. The BET results of the sample. 

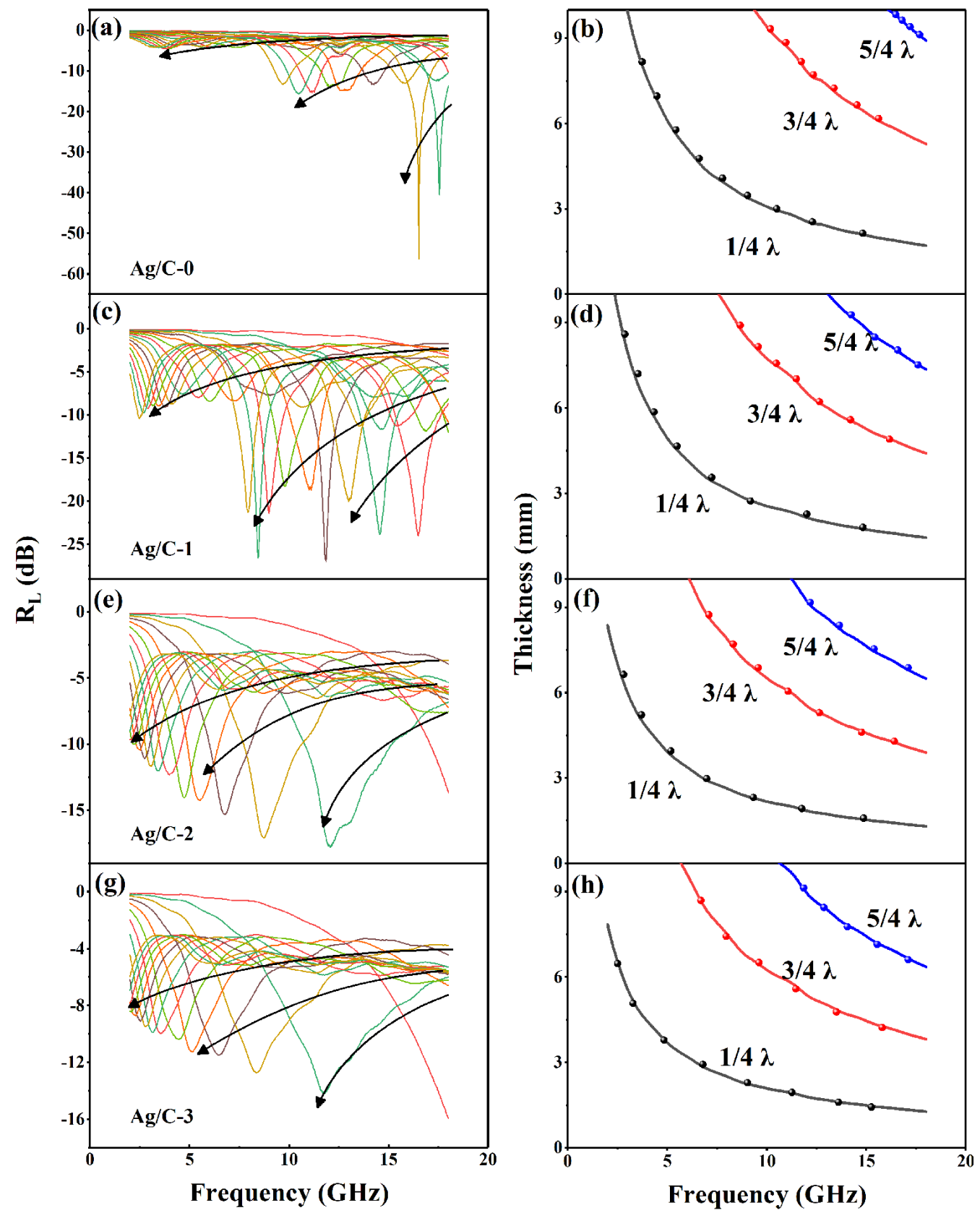

Figure S4. Optimal $R_{L}$-thickness curve and 1/4 wavelength function curve. 

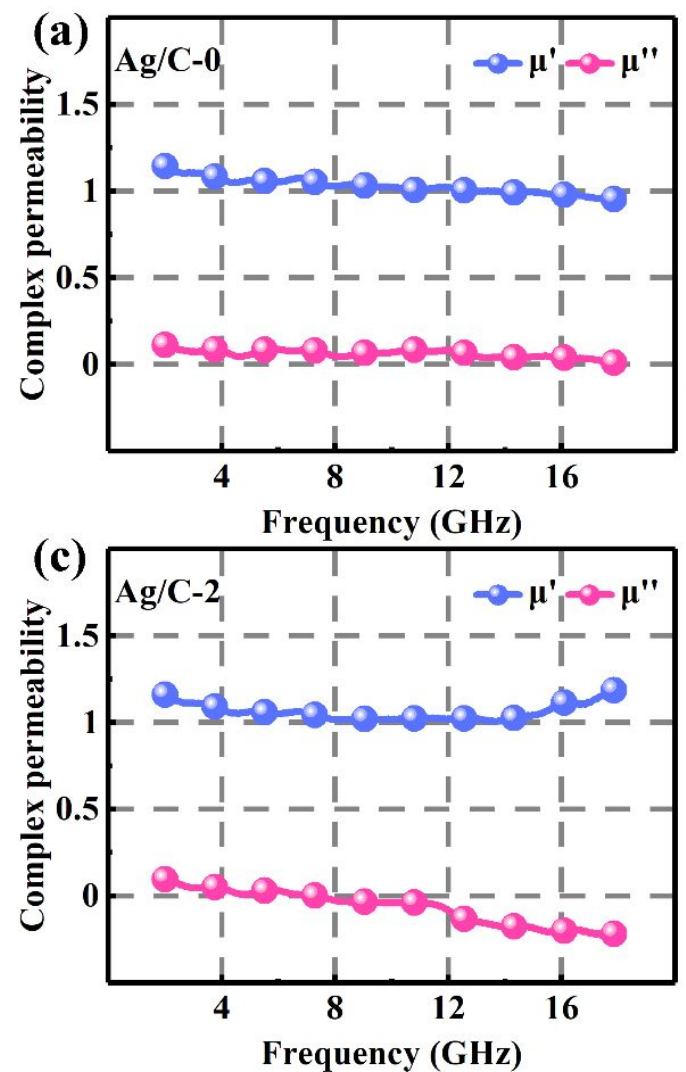

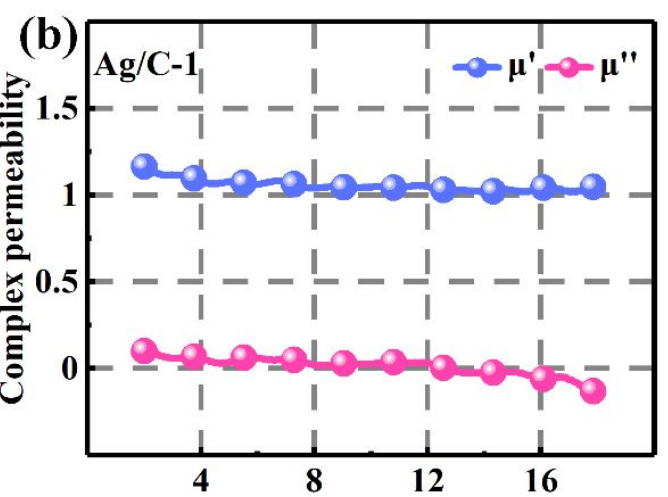

Frequency $(\mathbf{G H z})$

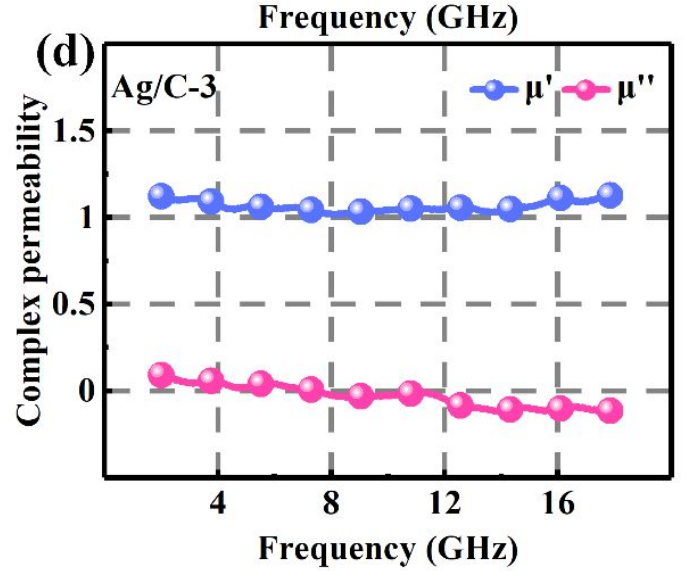

Figure S5. Permeability parameters of Ag/C-0 (a), Ag/C-1 (b), Ag/C-2 (c) and $\mathrm{Ag} / \mathrm{C}-3$ (d).

The data of the real part $\mu^{\prime \prime}$ and the imaginary part $\mu^{\prime}$ of magnetic permeability are close to 1 and 0 respectively, and only fluctuate slightly with the change of frequency. This fluctuation may come from the magnetic moment in disordered carbon materials. The $\mathrm{H}$ atom attached to the zigzag edge of nano-graphite and the vacancy defects in disordered carbon interact with impurities $(\mathrm{H}$ or $\mathrm{N})$ to produce magnetic moment, which leads to the change of magnetic permeability. ${ }^{1}$ Compared with the complex permittivity, the effect of permeability can be ignored. 

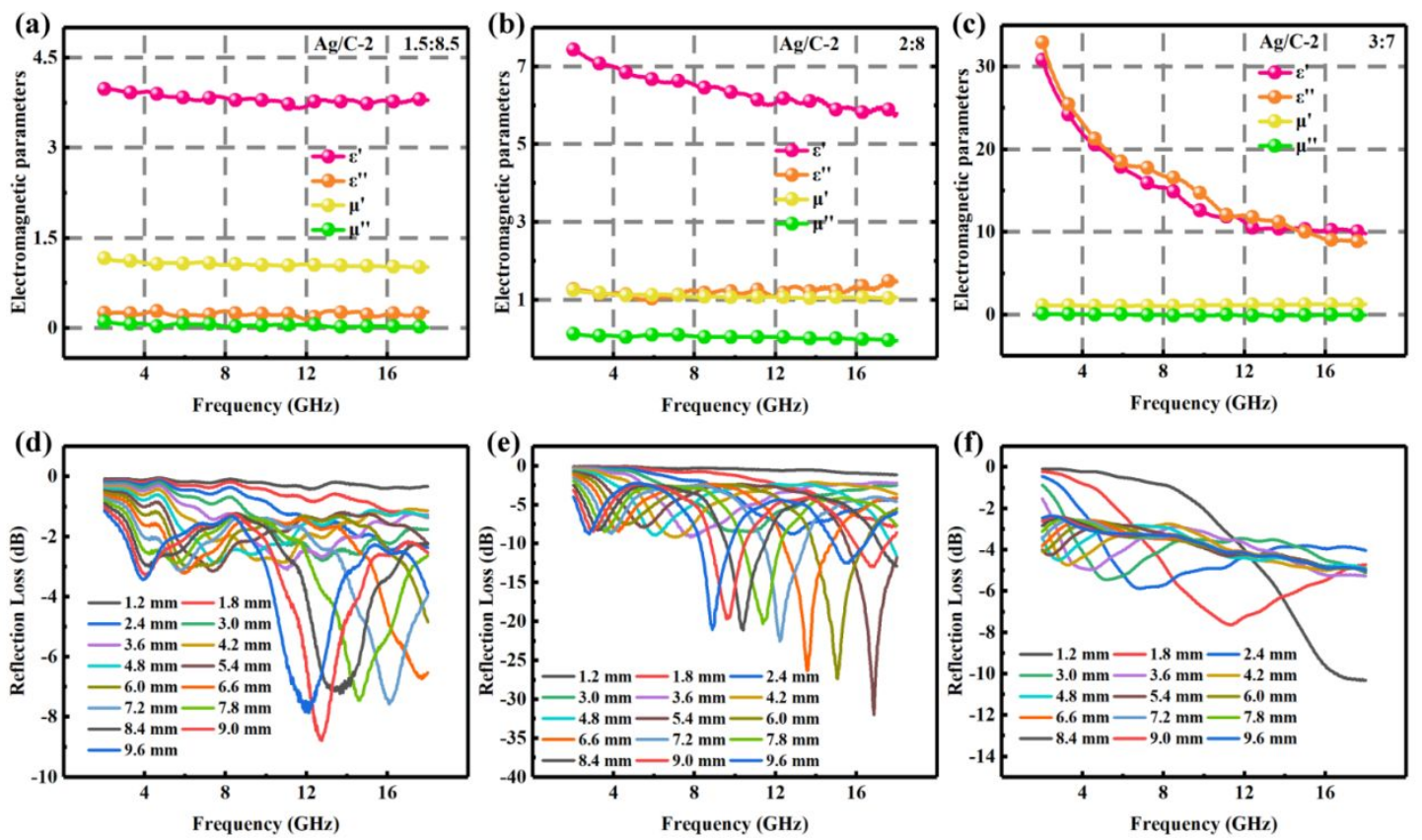

Figure S6. Electromagnetic parameters and MA performance of $15 \mathrm{wt} \%$ (a, d), 20 $w t \%(b, e)$ and $30 w t \%(c, f)$ filling ratio. 


\section{References:}

(1) Ma, S.; Xia, J. H.; Srikanth, V. V. S. S.; Sun, X.; Staedler, T.; Jiang, X.; Yang, F.; Zhang, Z. D. Magnetism of amorphous carbon nanofibers. Appl. Phys. Lett. 2009, 95, 263105. 